\title{
Features and Usefulness of Alipay
}

\author{
Mubshira Mushtaq \\ University of Management and Technology, Pakistan \\ Kalsoom Ashfaq \\ University of Management and Technology, Pakistan \\ Humeria Almas \\ University of Management and Technology, Pakistan \\ Iqra Qadeer \\ University of Management and Technology, Pakistan
}

\begin{abstract}
In virtual market and advanced technology, mobile payment application Alipay emerged prominently having strong competitive edge over rivalry. This application was initiated by Alibaba and nowadays leading with market shares. Its quite common and useful in everyday life especially in china where payments and receipts are surrounds QR (Quick Response) codes. This application just adds more convenience to routine life to quite big transactions. People of all categories and occupations are using Alipay in china. Other than china this application is also diversifying its roots internationally. Alipay is very famous \& popular electronic application in china. Alipay is safe, simple \& convenient application. It is now in trend. Alipay technology is at maturity level in china. It is very useful in daily life activities like online shopping, in restaurants, booking of tickets, for business purposes, for home delivery of food. Alipay has following features like security, even - handed, productive $\&$ forthrightness.
\end{abstract}

Keywords: QR codes, mobile payment application, TAM, market leader, usefulness and effectiveness in everyday life, e-business

\section{INTRODUCTION}

Alipay technology firstly introduced in china. It is the unique and advanced payment technology which came rebellion in china. Alipay technology is at maturity level in china. Alipay technology is a platform through which online payment can be done through mobile phones. In other words, it is a mob payment technology. In this technology era, where the internet is widely used and is advancement in modern technologies is at its peak likewise internet payment, mob payment makes revolution in ultra-advanced payment method in china, current year. The foremost focus of this study is to inspect the consequences or reaction of consumer's probability, realized facility of use, recognize effectiveness and reaction on user's goodwillness to utilized Alipay and using a structural equation modelling.

The boost of mobile payment technology is just because of internet popularity. The aggregate value of internet users expand due to the mobile users' value also expand.

Alipay is now on trending in china just because of ease \& convenience of payment with mobile instead of direct cash. All of basic necessities, desires \& wants for instance online shopping, groceries from stores, eating food from restaurants, particularly e-commerce, etc. Alipay cover up all the exposures. QR code is scanned for accomplishment of transaction. 
The national economy of China established and enlarged speedily just because of boom in mobile payments and electronic commerce. Alibaba, the leader of Chinese e-markets, established Kwang Kunjie (single's day), single day online sale on November $11^{\text {th }}$ that is same to black Friday after thanksgiving in the United States. On this eleven day, Alibaba's aggregated revenue or income from entirely of its plat form has been 91.2 billion Yuan (US $\$ 13.68$ billion), which included 232 countries and 467 million arranges \& organized sequence. These statistics indicates the world - wide tracks for one day electronic transaction extend ${ }^{[1] .}$

Alibaba's remarkable victory resulted first the implementation of Alipay that Alibaba was introduced in 2004. Alipay delivers superior facilities and demanded no transition wages because of these services permit the customer to validate their gratification with goods they buying ahead liberate cash to seller.

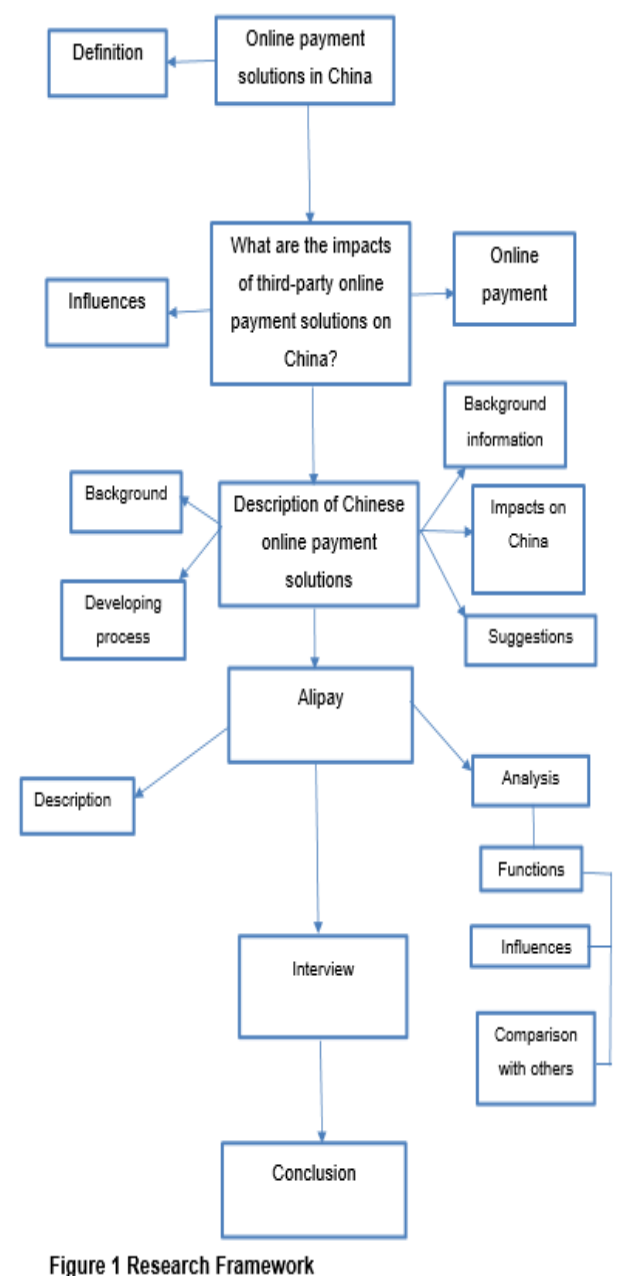




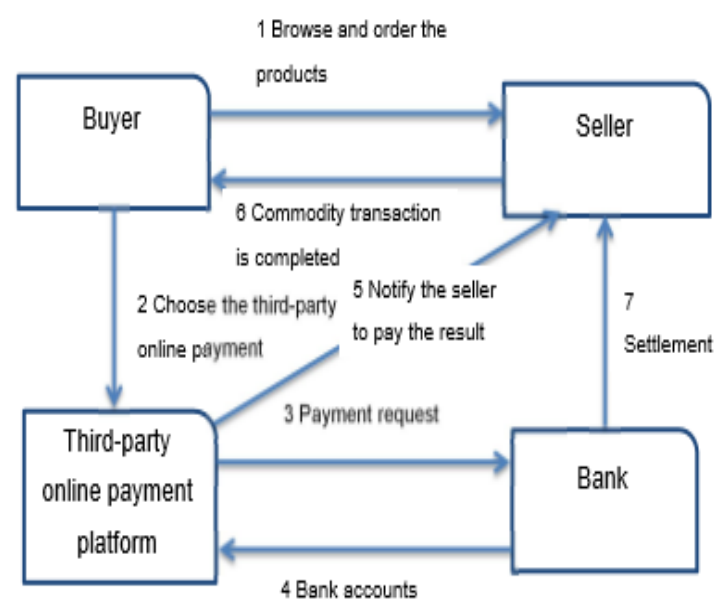

Figure 2 Business procedure of online payment model

The quality of foreignness make Alipay market leader because they give China's financially week customer supportive laws and regulation. Alipay is most appealing technology for customers to give it's more collective-users-friendly facilities. Alipay is distinctive and exclusive third payment platform. The idea behind third party payment was cashless china or wallet less china. Alibaba introduced its own platform that is Alipay application for convenience. In china, every shop from street hawkers to big shops, services, etc. all facilitate customers with Alipay's payment; All user have to scan its QR code and its done in a blink of eye. Due to major transactions to and by Alipay, due to Alibaba it's not just popular and leading in china only but also diversifying internationally. China's mediator clearance size enhanced to approximately eight trillions Yuan (US \$1.2 trillion) in 2014 with growth of $50.3 \%$ compared $t$ the 2013. Alipay have leading this speedily enhancing extension of $50.3 \% 0$ compared to online payment, with a $49.6 \%$ market share or $3.87 \%$ trillion Yuan, indicate in statistics ${ }^{[2]}$.

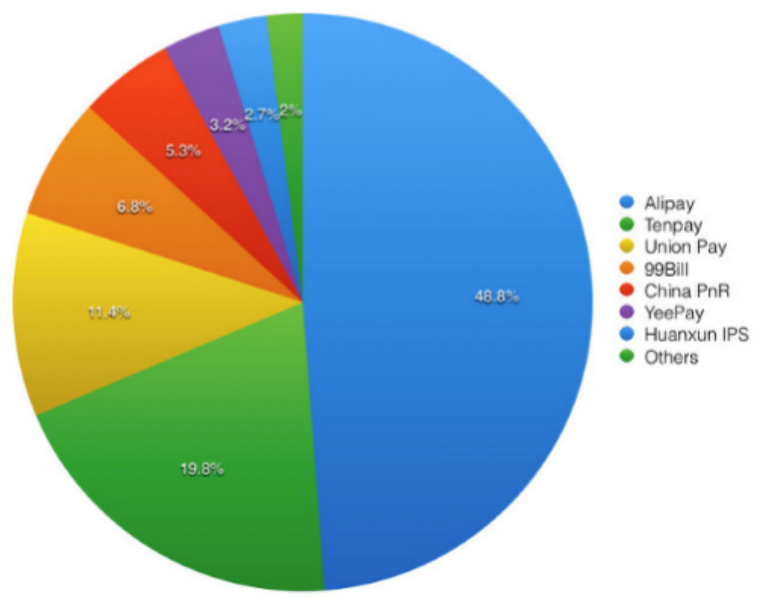

Alipay's market share (Lockett2015)

Alipay online payment method is being used worldwide. In china Alipay powerful bonding back empowers Alibaba to enhance its e-market shares, and also empowers customers in worldwide shopping online with Alipay payment method. Alipay also became market leader in electronic business with brand new competitive edge. Alipay 's durable achievement can be reasonable provided its ease of use, achievements deliberated promoting struggles, due to the 
worth configuration implicit on reticulation dealings alongside dissimilar contribution of specific thing is role to well - grounded appearing electronic-business dealings[3].

\section{Rivalry Competition}

With the boost in online mobile payment, china introduced two phone payment applications for purpose Alipay and WeChat which take the share of market to $90 \%$ up. With these mobile payment applications the power of competition enhanced shares of market. Nowadays, the bulk transaction volume of online mobile payment, Alipay is powerful as compared to WeChat but on magnitude of clients WeChat is powerful as compared to Alipay.

Both of companies pursue to introduce new and appealing series of application, marketing measures and enhance its functions such as movies, mobile games, videos, etc. in competitive market environment, resident holds "currency votes".

How to recognize the customer's functional desires, to increase the customer's product involvement and increase customer adhesiveness is the key role for companies to get competitive edge. Main points of research relay on the Class Technology Acceptance Model (TAM).

This study focus on providing the hypothetical reference for companies to increase the fierce and competitiveness of companies.

Section 1: Literature Analysis

Section 2: Research Frame Work And Data Collection

Section 3: Observation and Confirmation

Section 4: Features of online Third Party clearance System for Electronic Commerce

\section{LITERATURE ANALYSIS}

In literature review, we uses Technology Acceptance Model we draw a inter connection between faith, belief, behavior to describe \& forecasting the affirmation of new methods among capable customers.

Technology Affirmation Method describes two key elements:

I. Effectiveness

II. Realized facility of use

Effectiveness contemplate the degree to which one being can think to utilize the technical system to enhance their implementation, while considering the Realization of use contemplate to which one person ponder and agreed that utilizing a particular technical system without any struggle and strain. In this prototype, thinking indicates or shows the subjective either optimistic or adverse sentiments, when individual utilize the model while ambition return the quantifiable expand to which single human being are obliged to get hold certain \& specific responses ${ }^{[5]}$.

TAM shows following 3 specific ideas to speculate client acceptance of mechanization.

i. Whenever a consumer accepts a particular technical method is deliberated by intent determination and objective, intent determination is distributed by the consumer orientation and recognized effectiveness.

ii. The viewpoint is to together deliberated by recognize effectiveness and recognize facility of use while recognition of effectiveness is deliberated by recognize facility of use and outside parameter. 
iii. Recognized facility of use is deliberated by exteriors parameters are by main elements that can be distinguish in a particular circumstances.

\section{RESEARCH FRAMEWORK AND DATA COLLECTION}

Qualitative and Quantitative are the two methods to be considered in research framework. Qualitative research focus to discover intense logics, motivations and viewpoints from the research. These are following ways of qualitative research:
A. Data Collection
B. Interviews
C. Observations

For this review research paper we considered the secondary data.

To introduced for investigating the effects on online payment clarification. In research there are two primary approaches

- Deductive approach

- Inductive approach

The contrast among these approaches is that inductive approach based on hypothesis data. Secondary deductive approach is to evaluating how a hypothesis work in a data

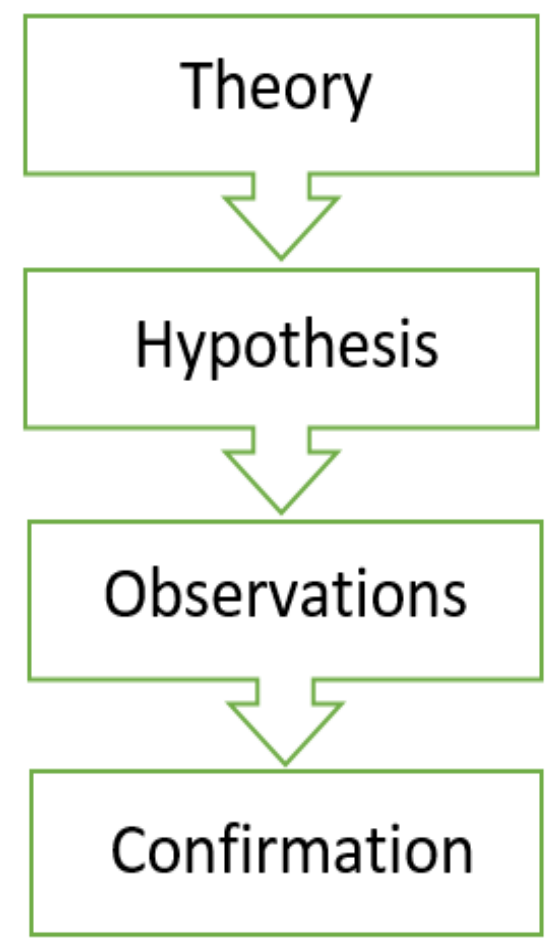

Figure: Deductive Approach

We selected deductive approach in this research paper.

- Recognize facility of use is positively interconnected to recognize effectiveness.

- Recognize facility of use is positively interconnected to consumer behavior.

- Recognize facility of user is positively interconnected to intent.

Previous study has shown the accurate and reasonable choosing of exterior variables plays a vital part in the rational clarification of the model in a specific research condition ${ }^{[7] .}$ 


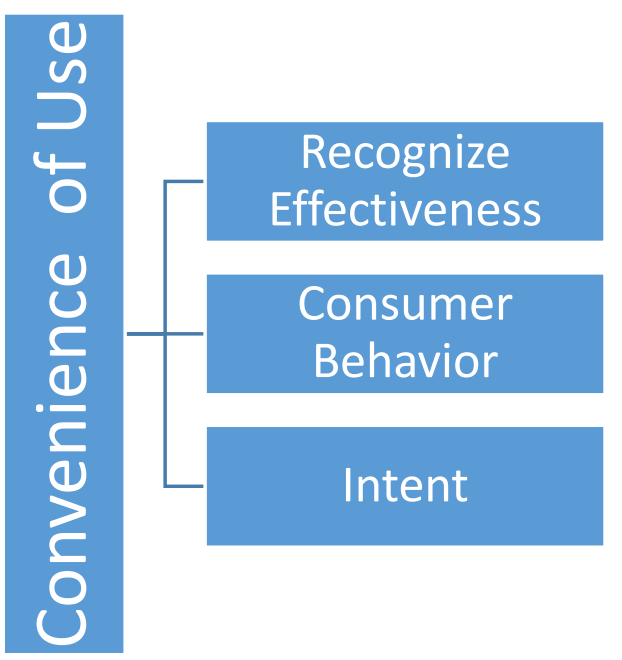

\section{DATA OBSERVATION AND CONFIRMATION}

We analysis or inspect the data from Creswell (2009), the focal point of the interview is to investigate the opinion exposures, inspiration of individual human beings by collection of this data from some different people of different occupation experiencing their life with Alipay for more than three years.

\section{University Student}

As the university student has the largest and deeper experience for third party electronic payment way-out in china. According to them they found it really convenient in everyday life instead of cash. Its amazing either to transfer money or for online shopping of foreign products timely. They hope Alipay can cooperate with more overseas sites.

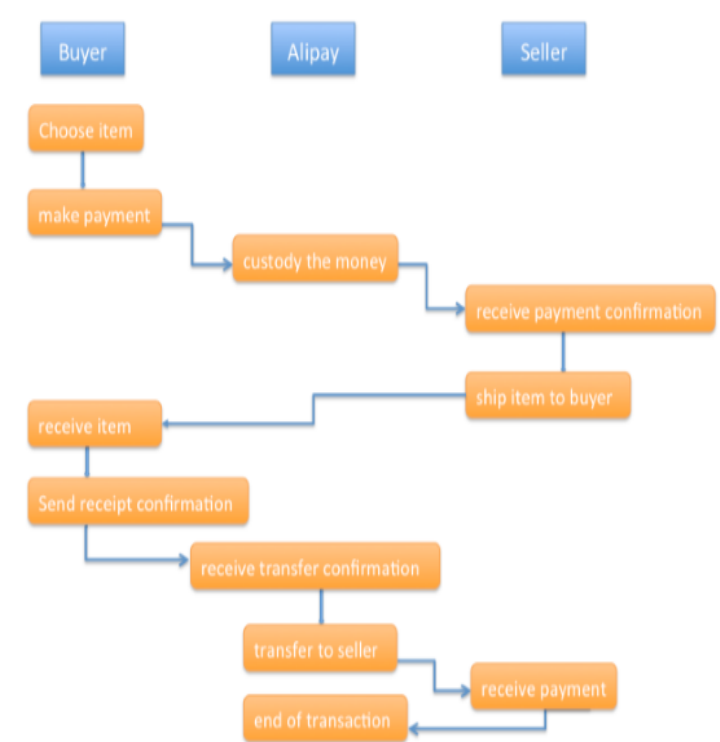

Figure: A straight transaction among a non-seller (sender) and non-buyer (receiver) where money is straightly moved \& carried via Alipay.

\section{Business Person}

Such category can portrays the people who work in e=commerce. He prefer cash over Alipay in his personal life but for his job his most of receipts and payments relay on Alipay as his most customers use it. Moreover, he personally thinks its more timely and easy then using bank foe every transactions. 


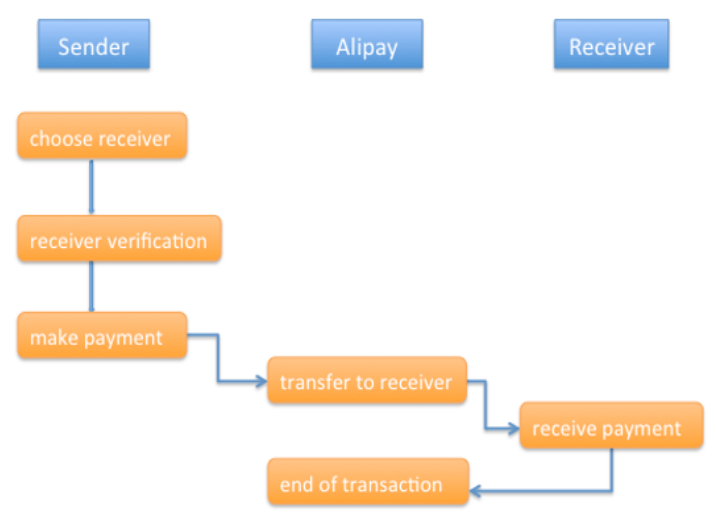

\title{
Bank Employee
}

choosing as respondent is that she operate in the bank and she has the very extended understanding for utilizing the Alipay She think it can reduction or usage of time to search the money and for release alterations. Her desire for the recommendations is that the Alipay can give further concentration to the safety, not to impose the evacuate charges and have further conspire to the banks because of job. Because of the rivalry attached the electronic payment resolution, the online bank distribute the purpose of electronic payment, attach implementation of the payment method platform, in sequence to give clients with suitable electronic payment with applicable to essential method of bank utilities rivalry, collaborating with the Alipay which can allot users funds and implement simultaneously.

\section{Working women}

As a working women the respondent speak that the most slam on her entity is she can relish further leisure time after that she free from job, she don't want to waste any hours to buy juice or electronic fee and she can utilize additional hours for herself.

\author{
FEATURES OF THIRD PAYMENT PLATFORM FOR E-COMMERANCE \\ $\checkmark$ Security \\ $\checkmark$ Even-handed \\ $\checkmark$ Productive \\ $\checkmark$ Forthrightness
}

\section{Security}

The third- force electronic clearance determination has the proliferate money, which can begin a complete safe clearance platform. Because to the third-force electronic payment utilizing the further improved electronic clearance methods, combine to all of bank clearance entrance, the financial account or pin code that client insert in the mediator policy will straightly link the customer account in bank, moreover the bank give the clearance safety. In spite of, the mediator clearance policy have own their security defensive system attached to SSL127 encoded system and PKI channel of key, giving the safe clearance dependability for the user. (Yin \& Tian 2009.)

\section{Even-Handed}

Third-force clearance policy construct a beneficial, assurance deal platform for the purchaser and dealers by keeping the third-party clearance policy .As ,it can keep the useful dealing information from the dealers and user, giving the warrantee to secure the authorized equity and scrutiny of both. (Yin \& Tian 2009.) 


\section{Productive}

As a self-sufficient mediator clearance policy, it have developed correspondence of connections with electronic-commerce website and banks also. If the client buy from the electroniccommerce site which have collaboration with the mediator clearance policy, it would gave an equal payment front end, whatever the client's account associated with bank, all can utilize front end buy, which is useful for the consumer's functions. (Yin \&Tian 2009.)

\section{Forthrightness}

The mediator clearance policy is an free hand system, giving clients with assistance of bank vehicles and the broad variety of more kinds of payment utilities. furthermore, the payment intervals also give a different alterations, not only it can assist all types of bank credits with the personal computer 18 console to payment, but moreover help payment of mobiles, phones and other types of console functions .(Yin \& Tian 2009.)

\section{CONCLUSION}

This review research concluded that Alipay is extremely important in individual life to make it smooth especially in china and later on for rest of the world due to greater shares and demand. Its ease to use and popular to everyone. Its features and usage is very time saving in this fast era of technology and speed. One's daily life activities relay on it either from getting basic services or just basic products to big transactions. Hence, Alipay's has a vital role in life of people and is leading market share in e-business.

\section{References}

QQ Finance News. The successful performance of Alibaba in Kwang Kunjie 2016

Alipay about Alipay. Available online http:/ /global Alipay.com / about / announcements.htm (accessed on January 2016)

Choi, Y. Introduction to the special issue on "sustainable E-Governance in Northern Asia: Challenges for Sustainable innovation" technol. Forecast. Soc. Change 2015, 96, 1-3

J. R. Clark, D. R. Lee, "Government transfers and inequality: An anatomy of political failure", J. Public Finance Manage., vol. 8, pp. 265, 2008. Show Context Google Scholar

A. Muk, C. Chung, "Applying the technology acceptance model in a two-country study of SMS advertising", J. Bus. Res., vol. 68, no. 1, pp. 1-6, 2015. Show Context CrossRef Google Scholar

The role of Alipay in commerce in China Facilitator of Trust or Abuser of Big Data? M.A.Th Werker MA Asian Studies: Chinese Studies MA Thesis Professor Dr. F. Schneider 30-06-2017

Third-party online payment solutions in China Case study: Alipay

LAHTI UNIVERSITY OF APPLIED SCIENCES Degree Programme in Business Information Technology Bachelor's Thesis Spring 2017 Qian Yang

Lahti University of Applied Sciences Degree Programme in Business Information Technology 